written recitations, and 'tests,' which resemble the written examinations, but are less severe.

2. The purpose and method of the examination should be fully explained to the pupils, and their mistakes and failures should be pointed out.

3. The questions set should be adapted to the age and ability of the pupils, easy enough to encourage them to attempt all, and difficult enough to call for their best efforts; should pertain to the work actually done; should be explicit, concise, logical, and call for thought and a mastery of principles, as well as for memory.

4. Too much importance should not be attached to the results. They should be reckoned as only one element, among several, in determining the standing of the student, and his fitness for promotion or graduation. They should never be made the basis of ranking, or the sole ground of promotion.

5. They should always be regarded and treated as simply one means or device in the process of education, and should never be treated as if they were the goal to be gained. They are a means, and not an end.

6. They should not be so severe or prolonged as to overtax the students' powers, should be conducted with absolute fairness and impartiality, as well as with good sense in regard to time, place, and circumstances, and proper allowance should be made for any exceptional circumstances, such as illness on the part of the student. The 'final' examination should be held long enough before the close of the term to allow the teacher to make the proper use of the results before the class separates.

Thomas J. MORgan.

IN the current discussions on the use and the abuse of examinations, it seems frequently to be assumed that their one great purpose is to test, - to furnish a basis for estimating the pupil's knowledge and ability, and the teacher's skill and success in instruction. If this were really the only purpose they serve, it would be easy to justify them, notwithstanding the fact that some evils undoubtedly flow from them. These evils do not exist in examinations per se, but are faults of administration; and, if a teacher proposes to abolish them on the ground that they encourage immorality, he utters an indictment of his own professional skill.

But admit, with certain extremists, that examinations have no justifiable use as tests ; that, for example, a pupil's fitness for promotion, or for learning a subject, is best determined by the teacher's personal knowledge, without any formal test : even then the examination can hold its ground, regarded either as a motive or as a discipline.

I feel sure that my experience in the management of public schools has taught me that the intellectual tone of a school cannot be kept at the proper pitch by any other motive. Even the best of pupils need to feel that they must study with a view to rendering a formal account of their opportunities. Here, again, the stress may be too great; but this is simply a fault of administration, which is a direct reflection on professional skill.

But leaving also the motive power and value of examinations out of account, they have a third and adequate defence in the fact that they afford a discipline of incomparable quality. The ability to render a clear, exact, and comprehensive account of what we know on a given subject, under some stress, or in view of something important depending on the result, is an endowment of supreme importance; and I know of no instrument for this purpose save a judicious examination.

As it seems to me, the only debatable question in the case is that of use and abuse : it is simply a matter of administration.

W. H. PAYNE.

THE purpose of all education must be the development of thought and character in the widest sense of these terms, - " the generation of power."

Examinations are of use only in so far as they are in harmony with this general purpose. They are a great power for good or evil ; they may be made a blessing or a curse to schools. An examination of pupils conducted by a supervising officer should have a threefold aim :-

First, It should be made a test as far as the pupils are concerned. Right here comes the danger of all examinations. What shall the test be? Quantity of knowledge? Then 'cramming' will be the inevitable result; and the superintendent who thus plants thorns and thistles has no right to expect them to bring forth grapes and figs.

The examination must test power, and not mere quantity of knowledge, - power to do intellectual work. As all food that is eaten is not converted into physical force, so all knowledge acquired is not converted into mental power. The test-question in the former case is, not "How much have you devoured?" nor even "How much do you weigh ?" but "How much can you lift?" So in the latter case it must be, not "How much do you remember?" but "How much can you do?"

The examination, therefore, should not require a mere reproduction of what the pupil has learned, but it should test his power of dealing with new questions and problems closely allied in principle to those which he has studied.

Secondly, It should stimulate the pupil to work in right lines. The pupil will work for the examination, and it is right that he should. If by working for it his work is wrong, the fault lies with the examiner and the examination. A superintendent has it in his power in this way to direct, in a large measure, the study of all the pupils in his schools.

Thirdly, It should test the character of the teaching, and should direct the work of the teacher. The teacher, like the pupil, will work for the examination to a very large extent. That which is made the chief test in the examination will be the motive of work with both teacher and pupil.

The examination is therefore a powerful lever, in the hands of a competent superintendent, to force school-work into right lines.

Thomas M. BALliet.

\section{THE ASSOCIATION OF OFFICIAL AGRICULTURAL} CHEMISTS.

THE fourth annual meeting of this Association was held in the Library of the Department of Agriculture, Washington, beginning Aug. I6, and lasting three days. The president, Dr. E. H. Jenkins of Connecticut, in his opening address, congratulated the Association on the success which had attended its efforts in securing the adoption of uniform methods for the analysis of fertilizers. $\mathrm{He}$ also recommended that the Constitution of the Association be amended so as to include chemists of agricultural colleges, and all official chemists having control of fertilizers, dairy products, and agricultural products in general.

The first business of the session, after listening to the President's address, was the reception of the report of the committee on fodders and feeding-stuffs, of which Prof. G. C. Caldwell of Cornell was chairman. The committee had sent out a number of samples of fodders and feeding-stuffs for comparative analysis, and the results obtained were presented. They showed that in the same sample widely different results were obtained by different analysts. These variations showed the necessity of adopting a strictly uniform method of analysis. Such a scheme was reported by the committee, and, after discussion and amendment by the Association, was adopted to be used by all analysts connected with the Association during the coming year.

The report of the committee on dairy products was presented by Dr. H. W. Wiley of Washington. The committee had sent out various samples of butters and butter-substitutes for examination by members of the Association. The tabulation of the analyses, as in the preceding cases, showed wide variations in many particulars. After discussion and amendment, the following method of analysis for butter and milk was adopted. For butter, preliminary examination with polarized light and selenite plate was recommended, while it was stated that the melting of butters and butter-substitutes, and their subsequent examination after cooling by polarized light, appeared to have no value as means of qualitatively sorting butters and butter-substitutes. The method of determining the specific gravity of the butter-fat at $40^{\circ} \mathrm{C}$., in a picnometer, was adopted. For Reichert's method, the saponification is to be made in the flask to be used subsequently in the distillation, saturated solution of potash with a small amount of alcohol to be used, and the fat-acids subsequently to be freed by phosphoric instead of sulphuric acid. 
For the estimation of fat in milk the Adam's method is recommended, viz., absorption of the milk by bibulous paper, drying, and extraction with ether. As alternate methods the procedure of Morse and Piggot or the lactocrite may be used. In the method of Morse the milk is dried by treatment with anhydrous sulphate of copper, and the fat extracted with light petroleum. Afterwards it is estimated volumetrically by saponification with standard alkali. In the method by the lactocrite the fat is separated in a centrifugal machine, revolving at the rate of 7,000 turns per minute, the milk being previously treated with an equal volume of a mixture of I part sulphuric and 20 parts acetic acid.

The method for analysis of fertilizers, with a few slight changes, remains as last year. The most important contribution in this matter was from Prof. M. A. Scovel of Kentucky, who showed that fertilizers containing nitrates could be treated by the Kjeldahl process, if the sulphuric acid used in digestion contained a certain portion of salycilic acid. By this means the total nitrogen existing in the three forms can be determined by an extremely simple and easy process.

The meeting was largely attended and full of practical interest from beginning to end. Two new committees, viz., one on fermented liquors and the other on sugar analysis, were appointed.

The following are the officers and committees for the coming year : President, Dr. P. E. Chazal ; Vice-President, Dr. W. J. Gascoyne ; Secretary, Mr. Clifford Richardson ; Members of Executive Committee, Dr. E. H. Jenkins, Prof. J. A. Myers ; Committees, on phosphoric acid, W. J. Gascoyne, N. W. Lord, W. E. Moses; on nitrogen, M. A. Scovel, N. T. Lupton, Wm. McMurtrie; on potash, J. A. Myers, Wm. Frear, E. H. Jenkins; on feeding-stuffs, G. C. Caldwell, W. H. Jordan, Clifford Richardson ; on dairy products, H. W. Wiley, S. M. Babcock, H. P. Armsby ; on fermented liquors, W. B. Rising, C. A. Crampton, G. F. Fellows; on sugar analysis, W. C. Stubbs, N. T. Lupton, H. W. Wiley.

\section{ALASKA LETTER.}

IT is strange that so little is known in the United States about Alaska. It has been a possession of our government for twenty years, and even now interest in it is only beginning to be developed. Yet in it we have by far the most remarkable of all our territories. Its area is not less than 60o,ooo square miles, or one-fifth of that of the United States proper. It is equal in extent to all the New England states, all the middle states, Ohio, Indiana, Michigan, the Virginias, the Carolinas, Tennessee, Kentucky, and Mississippi. Sitka is as far from the parallel of the extreme western boundary of Alas$\mathrm{ka}$ as it is from the parallel of Eastport, Me. The present governor of the territory estimates its population to be $35,26 \mathrm{I}$, including whites, creoles, and natives. Of this number, Io,60o, including 3 , IOo whites, dwell in south-eastern Alaska, the part accessible to tourists.

The native race of south-eastern Alaska is the Thlinket. The Thlinkets are far superior, intellectually and industrially, to the North American Indian. They are variously said to be of Asiatic and Aztec origin, but the majority of observers believe them to be related to the Chinese. They are skilful workers in wood and metals, shrewd traders, and very amenable to civilizing influences.

The climate of south-eastern Alaska is any thing but Arctic. The observations of Sergeant John J. McLean of the Signal Service at Sitka, for the year ending Aug. 3I, I886, showed an average temperature of $44^{\circ} .8 \mathrm{~F}$. The maximum was $72^{\circ}$, reached both in July and August, and the minimum $4^{\circ}$, reached in January. The rainfall is very heavy, often being more than roo inches per annum.

Alaska's resources are timber, mining, furs, and fisheries, but as they are only just being measured, it is useless to quote figures concerning them.

The trip to Wrangell, Juneau, Sitka, and the great glaciers of south-eastern Alaska is now easily and quickly made by frequent steamers from the Puget Sound ports. During the summer season. there are weekly sailings, and the fastest steamer makes the round trip from Tacoma, W.T., in eleven days. Travellers should provide themselves with warm clothing, for it will be needed during the entire trip. Rubber boots or overshoes, a rubber coat, and a stout pair of walking-boots are desirable. The last-mentioned are necessary for climbing on the Davidson and Muir glaciers, and the rubber articles are a protection against the wet weather.

For maps of the coast, the British Coast Survey maps are to be recommended, and the 'Coast Pilot' is a most valuable aid in determining the various peaks, glaciers, and channels. Though numerous books on Alaska have been issued, no one of them is satisfactory. Lieutenant Schwatka's book does not treat of southeastern Alaska, and those that profess to do so are superficial and inexact. Hubert Howe Bancroft's 'History of Alaska' is important, but far from satisfactory.

Adequate educational provision for the native and white children has yet to made. The Thlinkets show great ability in industrial work, and it is a source of great satisfaction to hear that an organized course of industrial training is to be put in operation in the Sitka school at once. In the 'Circular of Information' of the Bureau of Education known as No. 2, I 882 will be found an interesting paper on 'The Neglect of Education in Alaska.' B. $\mathrm{N}$.

Sitka, Alaska, Aug. r.

\section{HEALTH MATTERS.}

Against Bergeon's Treatment. - Dr. Townsend and Dr. Hennessy report, in the Albany Medical Annals, nine cases of phthisis treated by gaseous enemata, after Bergeon's method. The reporters say that these cases, though few in number and somewhat incomplete, are deemed worthy of publication, as showing that this method of treatment seems as much of a failure in this dreaded malady as are others equally highly advocated at the present day. Besides these cases, four others have come under the observation of the writers, in three of which they personally superintended the administration of the gaseous enemata, the fourth being seen only once in consultation, but the records of which were accurately kept by the attending physician. With reference to all these cases, it is stated that after a fair trial of from two to four weeks it was deemed expedient and proper that it be discontinued for the two following reasons: first, it did no permanent - indeed it might almost safely be said not even transient - good; while, second, it was most disagreeable and annoying to the patients, who generally were the first to suggest, or even beg for, its withdrawal.

Chloroforming while Asleep. - In the August number of the Nerv Orleäns Medical and Surgical Journal is an editorial comment on the subject of chloroforming persons while asleep. The editor says that there are several points relating to the physiological action of chloroform which have an important bearing on the question. The condition of health and the age of the person are matters to be considered in regard to the possibility of chloroforming people while asleep. To adults in perfect health chloroform is a decided cerebral stimulant, and it may be stated as a rule, to which the exceptions are exceedingly rare, that healthy adults cannot be chloroformed while asleep, unless their sleep has been induced by exhaustion or hypnotic agents. Weakly adults and children take chloroform with less resistance, as the stimulant effect on the cerebrum is less in degree and shorter in duration. Weakly adults and those acutely exhausted by disease or injury may be chloroformed during sleep. Children may also be chloroformed while asleep, and especially if they are depressed on any account. The editor recently demonstrated to several physicians the ease with which chloroform could be administered to a sleeping child when in a state of depression. The case was one of cancer of the mesentery, in which the little patient had been exhausted by pain and restlessness. The victims of chloroform at the hands of burglars are usually at the time in good health. The more improbable, then, is the story usually told of such burglaries. Under all conditions anæsthesia by chloroform can be accomplished during sleep only by skilful administration. Overdosage at the outset will certainly awaken the sleeper. The ability of burglars to force the anæsthesia of several persons sleeping in the same room without raising an alarm is to be doubted. In regard to the impression which prevails that burglars impregnate the air of an apartment with chloroform vapor, so as to gradually anæsthetize all the sleepers at the same time, the editor says that the weight of chloroform vapor and the readiness with which it descends make it difficult to saturate the air of a sleeping apartment, especially one 